\title{
EFEITO DE DIFERENTES NÍVEIS DE PROTEÍNA BRUTA SOBRE O DESEMPENHO E COMPOSICÃO DE CARCAÇA DE FRANGOS DE CORTE MACHOS DE 21 A 42 DIAS DE IDADE
}

\author{
Effect of different crude protein levels on performance and carcass \\ composition of male broiler chickens from 21 to 42 days of age
}

\author{
Carlos Henrique de Figueiredo Vasconcellos ${ }^{1}$, Dalton de Oliveira Fontes ${ }^{2}$, Tatiana Zacché Batista Vidal'2, \\ Leonardo José Camargos Lara², Paulo Borges Rodrigues ${ }^{3}$, Roberta Juliana Costa Vasconcelos ${ }^{2}$
}

\begin{abstract}
RESUMO
O experimento foi conduzido em delineamento inteiramente ao acaso, para avaliar os efeitos da redução de proteína bruta (PB) com suplementação de aminoácidos essenciais sobre o desempenho e características de carcaça de frangos de corte machos da linhagem Ross, na fase de 21 a 42 dias de idade. Foram utilizados 720 frangos, distribuídos em 4 tratamentos e seis repetições com 30 aves cada. Os níveis de proteína bruta utilizados foram 21; 19 e 17 e 15\% de PB. A redução de proteína levou a um aumento linear dos teores de gordura e matéria seca. Houve ainda efeito quadrático dos níveis de proteína bruta, sendo para máximo ganho de peso, peso aos 42 dias e consumo de dieta os níveis de 19,28; 19,35 e 16,75\% de PB, respectivamente. Houve efeito quadrático sobre o rendimento de peito, estimando máximo rendimento para frangos alimentados com dietas contendo 18,28\% de PB.
\end{abstract}

Termos para indexação: Aminoácidos, proteína bruta, rendimento de cortes, carcaça.

\section{ABSTRACT}

A completely randomized experimental design was carried out to evaluate the effects of crude protein (CP) reduction of diets with essential amino acids supplementation on performance and body composition of male broiler chickens from 21 to 42 days of age. A total of seven hundred twenty broiler chickens were used. The birds were allotted in four treatments and six replicates of thirty birds each. The diet CP levels were 21, 19, 17 and 15\%. The reduction of protein led to a linear increase in fat and dry matter. There was also a quadratic effect of the CP levels; for maximum weight gain; weight at 42 days and final weight and feed intake. The maximum performance of these parameters were estimated for broilers fed 19.28; 19.35 and $16.75 \% \mathrm{CP}$ diet, respectively. There was a quadratic effect of $\mathrm{CP}$ level on breast yield, the maximum performance estimated for broiler fed $18.28 \% \mathrm{CP}$ diet.

Index termes: Amino acids; crude protein; carcass; carcass cuts yields.

(Recebido em 27 de novembro de 2009 e aprovado em 6 de abril de 2010)

\section{INTRODUÇÃO}

Os resultados experimentais registrados na literatura são variados e, às vezes, contraditórios quanto ao desempenho e à composição de carcaça de frangos alimentados com dietas contendo níveis de proteína bruta. Sabe-se que as exigências de frangos de corte não são de proteína bruta, mas sim em aminoácidos essenciais e ou quantidades suficientes de nitrogênio para a síntese de aminoácidos não essenciais.

Dentre os fatores dietéticos que influenciam o requerimento de aminoácidos, podem ser incluídos a concentração de energia metabolizável, o desequilíbrio de aminoácidos e o nível de proteína bruta da dieta (Leeson \& Summers, 2001)

O balanceamento adequado de aminoácidos e proteína para frangos de corte é de fundamental importância, seja pelo peso da proteína no custo total da formulação, seja pelo resultado esperado em função dos níveis de aminoácidos empregados. A formulação de dietas com base em aminoácidos digestíveis já é consagrada pelos nutricionistas e facilitada pela disponibilidade de aminoácidos industriais. Entretanto, ainda é utilizada uma certa quantidade de proteína bruta nas dietas, em função da importância também dos aminoácidos não essenciais.

De acordo com Skalan \& Plavnik (2002), as rações de frangos de corte devem ser formuladas para fornecer aminoácidos suficientes para a síntese protéica e o excesso destes pode resultar em queda na eficiência de utilização e aumento da exigência de aminoácidos essenciais. Isso ocorre pelo fato do excesso de proteína ser catabolizado na forma de ácido úrico. Esse processo

1Universidade Federal de Minas Gerais/UFMG - Escola de Veterinária/EV - 30123970 - Belo Horizonte, MG - carloshzoo@yahoo.com.br
2Universidade Federal de Minas Gerais/UFMG - Escola de Veterinária/EV - Belo Horizonte, MG

3Universidade Federal de Lavras/UFLA - Departamento de Zootecnia/DZO - Lavras, MG 
tem um alto custo energético; estima-se que, para incorporar um aminoácido na cadeia protéica gasta-se em torno de 4 mols de ATP e para excretar um aminoácido são gastos de 6 a 18 mols de ATP, dependendo da quantidade de $\mathrm{N}$ do aminoácido. Dessa forma, com aminoácido em excesso, a ave gasta energia para eliminar o excesso de N; energia que deveria estar sendo utilizada na manutenção corporal. Nesse contexto, uma definição do padrão da proteína ideal é de fundamental importância para tornar a deposição de proteína mais eficiente e maximizar a produção de carne de frango, uma vez que se não há aminoácido em excesso, haverá menor gasto de energia nos processos de excreção (Rostagno et al., 2006).

De acordo com resultados obtidos por Cromwell et al. (1996), a redução dos níveis de PB das dietas não prejudicaram o desempenho, mas as carcaças apresentaram maior conteúdo de gordura. Silva et al. (2003) também observaram aumento na percentagem de gordura na carcaça de frangos com a diminuição do teor protéico.

Também trabalhando com redução de proteína Rostagno et al. (2002), observaram que mediante a formulação de dietas com níveis mais baixos de proteína, usando a proteína ideal, é possível a obtenção de desempenho similar das aves alimentadas com dietas contendo altos níveis protéicos. A redução do conteúdo protéico em $2 \%$ resultou em um consumo de proteína $8 \%$ menor.

Por outro lado, alguns relatos na literatura têm mostrado piora no desempenho dos animais alimentados com dietas com baixos níveis protéicos; mesmo suprindo as necessidades em aminoácidos essenciais. Bregendahl et al. (2002) relataram que as aves alimentadas com dietas de baixa proteína tiveram piora no desempenho, na eficiência alimentar e maior concentração de gordura na carcaça. Da mesma forma, trabalhando com redução de PB, Rigueira et al. (2006) observaram que frangos de corte responderam linearmente aos níveis protéicos para as características de desempenho, recomendando-se um nível mínimo de PB de $20 \%$ para frangos de corte machos de 21 a 35 dias de idade.

Assim, esse trabalho foi realizado com objetivo avaliar os efeitos dos níveis de proteína da dieta sobre o desempenho e composição de carcaça de frangos de corte de 21 a 42 dias de idade.

\section{MATERIAL E MÉTODOS}

O experimento foi realizado no Setor de avicultura do Departamento de Zootecnia da Universidade Federal de Minas Gerais, localizado na Fazenda Experimental Prof. Hélio Barbosa, no município de Igarapé, MG. A temperatura máxima e mínima durante o experimento variou entre $28 \pm$ $3,5^{\circ} \mathrm{C}$ e $15 \pm 3,0^{\circ} \mathrm{C}$.

As aves foram alojadas em galpão de alvenaria com piso de concreto, dividido em boxes de estrutura metálica ( 60 boxes idênticos com $3 \mathrm{~m}^{2}$, sendo 30 boxes de cada lado) forrados com cepilho de madeira. Foi utilizado um termômetro de máxima e mínima, colocado no interior do galpão, para registro diário da temperatura.

Foram utilizados 720 pintos de corte, machos, da linhagem comercial ROSS de 21 aos 42 dias de idade distribuídos em 4 tratamentos e seis repetições, sendo alojadas 30 aves/boxe $\left(10\right.$ aves $\left./ \mathrm{m}^{2}\right)$. Até os 21 dias de idade as aves foram criadas com uma ração comum formulada para atender às exigências nutricionais das aves de acordo com Rostagno et al. (2005) As aves foram vacinadas no incubatório de origem contra a doença de Marek e aos 12 dias de idade, contra a doença de Gumboro via água de bebida.

Até os 14 dias de idade, as aves receberam aquecimento artificial, sendo uma lâmpada infravermelha por boxe. Durante os primeiros sete dias de alojamento, foi utilizado um bebedouro tipo copo de pressão para cada 30 aves, juntamente com um bebedouro pendular automático para cada boxe. Este último permaneceu até o período final de criação. Do primeiro aos 14 dias de idade foi utilizado um comedouro tubular tipo infantil para cada boxe.

O programa de luz utilizado foi o seguinte: 1 a 14 dias 24 horas de luz; 14 a 42 dias de idade, luz natural.

Foram utilizadas quatro dietas com diferentes níveis de proteína bruta. O percentual de proteína bruta das dietas foi de $21,19,17$ e $15 \%$ correspondendo, respectivamente, aos tratamentos $\mathrm{T} 1, \mathrm{~T} 2, \mathrm{~T} 3, \mathrm{~T} 4$ e $\mathrm{T} 5$. (tabela 5 )As dietas foram formuladas de forma a atender, às exigências nutricionais das aves de acordo com Rostagno et al. (2005), sendo as dietas de menores níveis protéicos suplementadas com aminoácidos (aa's) sintéticos (L-lisina; DL- Metionina; L-treonina; Ltriptofano; L-isoleucina, L-valina e L-arginina) de forma a manter constante a relação entre a lisina digestível e os demais aminoácidos essenciais até o nível mínimo de exigência. As rações foram suplementadas com casca de soja para manter constante o nível de fibra bruta da dieta e foram fornecidas à vontade durante todo o período experimental.

As aves foram pesadas semanalmente. $\mathrm{O}$ ganho de peso foi calculado pela diferença entre o peso aos 21 e aos 42 dias de idade. O consumo de ração foi 
determinado a partir da quantidade de ração oferecida, subtraindo-se a sobra no final do período experimental. Para o cálculo do consumo de ração foi considerado o número de aves mortas na semana. O cálculo de conversão alimentar foi feito a partir do consumo médio de ração e o ganho médio de peso das aves ao final da fase de criação.

Aos 42 dias de idade, foram amostradas aleatoriamente e abatidas 96 aves, sendo quatro aves de cada repetição. Portanto, foram abatidas 24 aves por tratamento, sendo que para as análises estatísticas cada ave foi considerada uma repetição. Essas aves foram utilizadas para determinação do rendimento de cortes e composição de carcaça. Para a determinação da composição de carcaça, cada carcaça, sem as vísceras, foi moída. Após homogeneização foram retiradas amostras que foram conservadas a $-12^{\circ} \mathrm{C}$ para posteriores análises.

Em razão da alta concentração de água e gordura na carcaça dos animais, as amostras foram submetidas, inicialmente, à pré-secagem em estufa com ventilação forçada a $600 \mathrm{o}$, por 96 horas, seguida de prédesengorduramento pelo método a quente, por quatro horas, em extrator tipo "SOXHLET". As amostras pré-secas e pré-desengorduradas foram moídas e acondicionadas em potes de plástico, para análises bromatológicas posteriores. As análises de matéria seca, proteína bruta e extrato etéreo das amostras foram realizadas de acordo com Silva (1990).

Para a avaliação do desempenho, o delineamento experimental utilizado foi o inteiramente ao acaso com 4 tratamentos (dietas) e 6 repetições, sendo cada repetição composta de 30 aves. Para a avaliação da composição de carcaça e rendimento de cortes o delineamento foi o mesmo, sendo constituído por quatro tratamentos e 24 repetições cada, sendo cada ave considerada como uma repetição.

As análises dos dados foram feitas por meio do programa SAEG. Os efeitos dos níveis de proteína bruta foram calculados por análise de regressão. Os graus de liberdade dos fatores foram desdobrados em seus componentes lineares e quadráticos para a escolha do modelo de regressão que melhor descreveu as observações.

\section{RESULTADOS E DISCUSSÃO}

Desempenho de frangos de corte de 21 a 42 dias recebendo dietas com níveis reduzidos de Proteína Bruta (PB).

Os níveis de PB na dieta influenciaram de forma quadrática o peso final, o ganho de peso e o consumo de ração (tabela 2). Os níveis de PB para máximo peso aos 42 dias, ganho de peso e consumo de ração foram de 19,35; 19,28 e 16,75\% (Figuras 1, 2 e 3) respectivamente. Em relação à conversão alimentar $(\mathrm{CA})$ houve efeito linear decrescente significativo, ou seja, diminuindo-se os níveis de $\mathrm{PB}$, houve piora na conversão alimentar.

De acordo com esses resultados, pode-se observar que níveis mais baixos de proteína bruta, levaram à diminuição no desempenho. As aves que consumiram dietas com níveis de proteína mais baixos aumentaram o consumo de ração; provavelmente, numa tentativa de suprir alguma deficiência nutricional. Esse aumento de consumo, não refletiu em aumento de ganho de peso, o que piorou a conversão alimentar desses animais. Pode-se observar que a redução da proteína dietética deixou as dietas nutricionalmente deficientes.

De maneira semelhante, Sabino et al. (2004) também verificaram efeito quadrático do ganho de peso com o aumento dos níveis de $\mathrm{PB}$; atingindo o máximo com $21,12 \%$ de PB na ração para frangos de corte machos dos 22 aos 42 dias de idade. A melhor conversão alimentar ocorreu com o nível de $21,70 \%$ de PB que, diferentemente dos resultados obtidos neste trabalho, apresentou efeito quadrático. Aletor et al. (2000) também observaram diminuição do ganho de peso e piora na conversão alimentar de frangos que receberam dietas com níveis mais baixos de PB.

De acordo com Namroud et al. (2008), reduzindose a PB abaixo de $19 \%$ resulta em diminuição do desempenho e consumo de ração de frangos aos 28 dias de idade. Cheng et al. (1997), de modo semelhante, observaram piora no ganho de peso e conversão alimentar de frangos de corte alimentados com dietas com níveis reduzidos de $\mathrm{PB}$.

Os dados apresentados no presente trabalho corroboram com Kamram et al. (2008) que também observaram aumento linear da CA e diminuição linear do ganho de peso com a diminuição da PB. Segundo Sklan \& Plavinik (2002), a queda no desempenho de aves alimentadas com dietas de baixa proteína se deve à deficiência de aminoácidos essenciais. No presente trabalho, todos os aminoácidos essenciais foram suplementados de acordo com as exigências preconizadas por Rostagno et al. (2005). Pode ser que essas exigências fiquem alteradas, ou as relações entre os aminoácidos sejam modificadas quando os níveis de PB são reduzidos. Todavia, houve piora no desempenho das aves quando o nível de PB da dieta foi reduzido. 
Tabela 1 - Composição percentual e valores nutricionais calculados das rações com níveis reduzidos de PB na fase de 21 a 42 dias de idade

\begin{tabular}{|c|c|c|c|c|}
\hline & \multicolumn{4}{|c|}{ Tratamentos/Níveis de PB } \\
\hline Ingredientes & $\mathrm{T} 1(21 \%)$ & $\mathrm{T} 2(19 \%)$ & $\mathrm{T} 3(17 \%)$ & $\mathrm{T} 4(15 \%)$ \\
\hline Milho & 55,97 & 55,97 & 55,97 & 55,97 \\
\hline Farelo de soja & 35,85 & 30,65 & 25,37 & 20,02 \\
\hline Óleo de soja & 4,65 & 4,65 & 4,65 & 4,65 \\
\hline Amido & - & 2,74 & 5,48 & 8,21 \\
\hline Casca de Soja & - & 0,83 & 1,69 & 2,57 \\
\hline Calcário & 0,84 & 0,83 & 0,82 & 0,81 \\
\hline Fosfato Bic. & 1,68 & 1,73 & 1,78 & 1,83 \\
\hline Sal comum & 0,41 & 0,41 & 0,41 & 0,41 \\
\hline Inerte & - & 1,32 & 2,39 & 3,22 \\
\hline Premix vit. Mineral $^{1}$ & 0,4 & 0,4 & 0,4 & 0,4 \\
\hline DL-Metionina & 0,181 & 0,24 & 0,30 & 0,35 \\
\hline L-Lisina & 0,024 & 0,19 & 0,36 & 0,53 \\
\hline L-Treonina & - & 0,047 & 0,13 & 0,22 \\
\hline L-Arginina & - & - & 0,08 & 0,26 \\
\hline L-Isoleucina & - & - & 0,06 & 0,16 \\
\hline L-Valina & - & - & 0,1 & 0,20 \\
\hline L-Fenilalanina & - & - & - & 0,13 \\
\hline L- Histidina & - & - & - & 0,019 \\
\hline L-Triptofano & - & - & 0,003 & 0,034 \\
\hline L- Glicina & - & - & - & - \\
\hline \multicolumn{5}{|l|}{ Níveis Nutricionais } \\
\hline Proteína Bruta (\%) & 21 & 19 & 17 & 15 \\
\hline EMA (kcal/kg) & 3,120 & 3,120 & 3,120 & 3,120 \\
\hline Cálcio (\%) & 0,84 & 0,84 & 0,84 & 0,84 \\
\hline Fósforo Disp. (\%) & 0,42 & 0,42 & 0,42 & 0,42 \\
\hline Fibra Bruta $(\%)$ & 2,91 & 2,91 & 2,91 & 2,91 \\
\hline Lisina dig. (\%) & 1,05 & 1,05 & 1,05 & 1,05 \\
\hline Met. + Cis. Dig. (\%) & 0,76 & 0,76 & 0,76 & 0,76 \\
\hline Treonina Dig. (\%) & 0,71 & 0,68 & 0,68 & 0,68 \\
\hline Triptofano dig. (\%) & 0,23 & 0,21 & 0,18 & 0,18 \\
\hline Isoleucina Dig. (\%) & 0,83 & 0,74 & 0,70 & 0,70 \\
\hline Valina dig. $(\%)$ & 0,89 & 0,79 & 0,79 & 0,79 \\
\hline Arginina Dig. (\%) & 1,35 & 1,19 & 1,10 & 1,10 \\
\hline Fenil.+Tir. dig. (\%) & 1,64 & 1,46 & 1,27 & 1,21 \\
\hline Gli + Ser. Total (\%) & 1,92 & 1,71 & 1,51 & 1,30 \\
\hline
\end{tabular}

${ }^{1}$ Suplemento Vitamínico-mineral expresso por Kg de ração::Vitamina A, 1.333.000 UI, Vitamina $\mathrm{D}_{3}, 166.700$ UI, Vitamina E, $1.667 \mathrm{UI}$, Ácido Fólico $36 \mathrm{mg}$, Ácido Pantotênico, $2.837 \mathrm{mg}$, Ácido Nicotínico, $4.000 \mathrm{mg}$, Biotina 3,34 mg, Vitamina $B_{6}$ (Piridoxina), $60 \mathrm{mg}$, Vitamina $B_{2}$ (Riboflavina), $459 \mathrm{mg}$, Vitamina $B_{1}$ (Tiamina), $80 \mathrm{mg}$, Vitamina $B_{12} 3.333 \mathrm{mcg}$, Vitamina C, $8.225 \mathrm{mg}$, Vitamina $\mathrm{K}_{3} 353 \mathrm{mg}$, Ferro, $20.070 \mathrm{mg}$, Cobre, $1.904 \mathrm{mg}$, Manganês, $3.700 \mathrm{mg}$, Zinco $16.464 \mathrm{mg}$, Iodo, $85 \mathrm{mg}$, Selênio, $24 \mathrm{mg}$, Colina, 21,67 g, Antioxidante, $25 \mathrm{~g}$, Bacittracina de zinco (ppm) 80, 12,50 g, Virginiamicina $3,33 \mathrm{~g}$, Veículo QSP $1.000 \mathrm{~g}$. (6kg / ton.) 
Tabela 2 - Desempenho de frangos de corte alimentados com dietas contendo níveis reduzidos de PB dos 21 aos 42 dias de idade.

\begin{tabular}{ccccc}
\hline \multicolumn{5}{c}{ Variáveis } \\
\hline Níveis de PB $(\%)$ & Peso final $(\mathrm{g})$ & Ganho peso $(\mathrm{g})$ & Consumo $(\mathrm{Kg})$ & CA \\
\hline 21 & 3,060 & 2,133 & 3,7811 & 1,773 \\
19 & 3,058 & 2,143 & 3,8703 & 1,806 \\
17 & 3,053 & 2,124 & 3,8891 & 1,846 \\
15 & 2,966 & 2,055 & 3,9199 & 1,893 \\
\hline CV & 1,574 & 1,965 & 1,737 & 1,235 \\
\hline Significância & $*$ & $*$ & $*$ & $*$ \\
\hline
\end{tabular}

* = Significativo $(\mathrm{P}<0,05)$

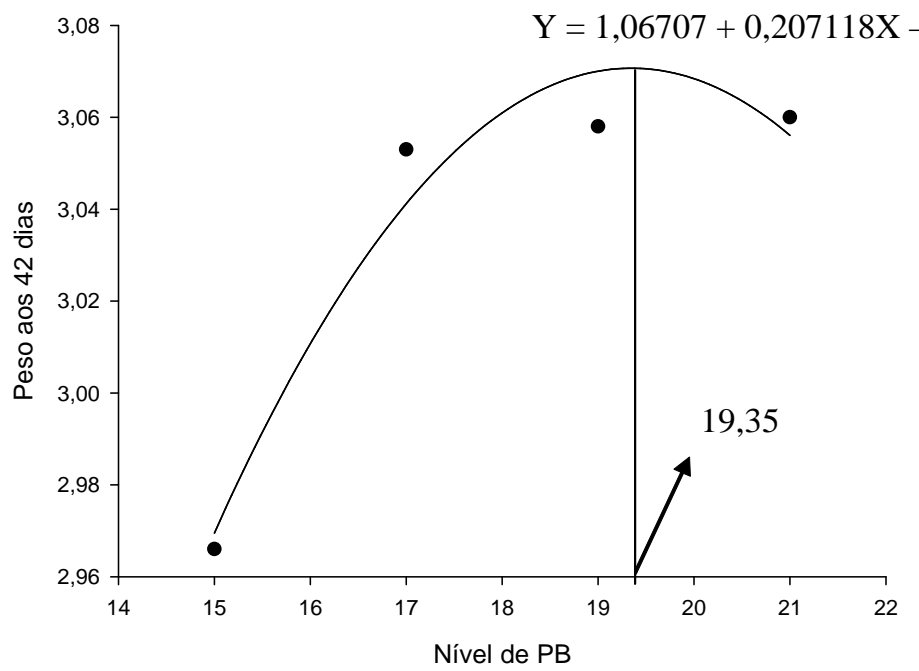

Figura 1 - Regressão do peso aos 42 dias (kg) de frangos de corte machos em relação aos níveis de proteína bruta das dietas (\%).

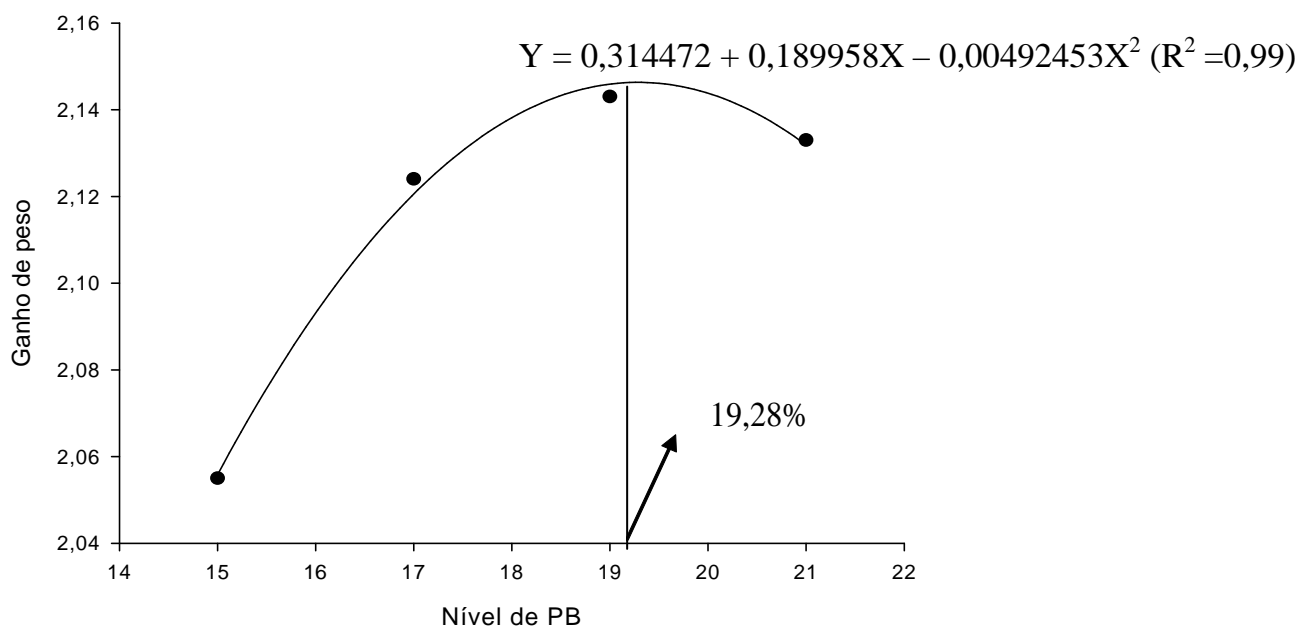

Figura 2 - Regressão do ganho de peso dos 21 aos 42 dias (kg) de frangos de corte machos em relação aos níveis de proteína bruta das dietas (\%). 


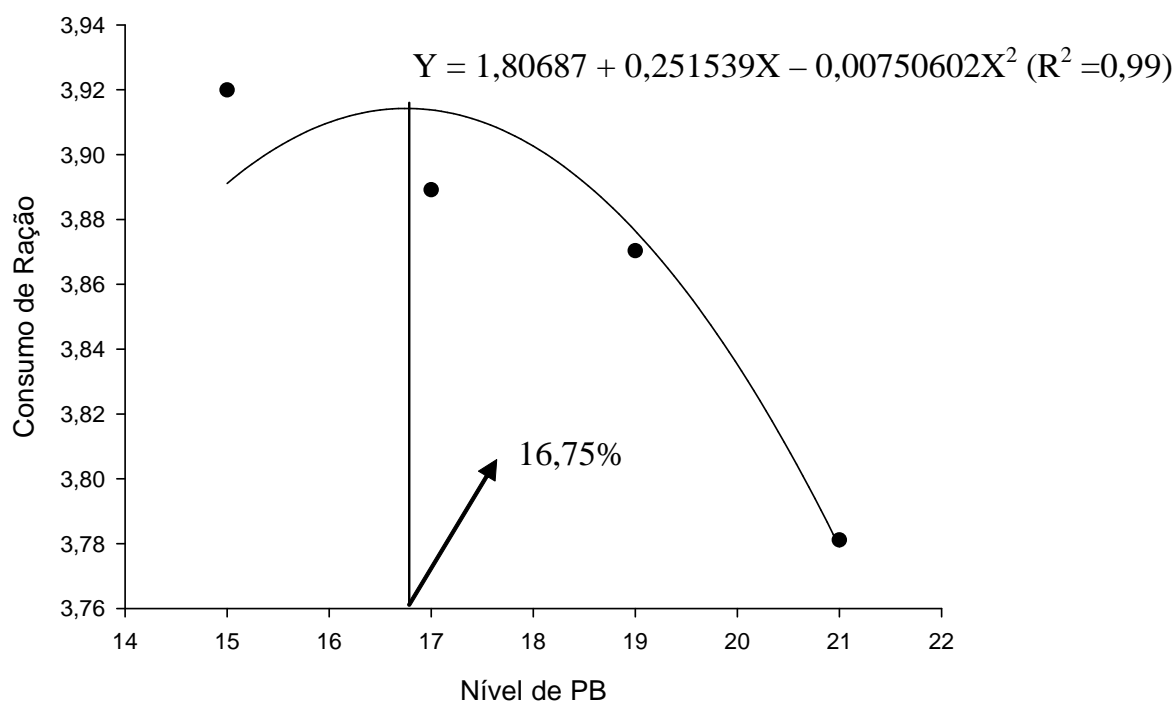

Figura 3 - Regressão do consumo de ração dos 21 aos 42 dias $(\mathrm{kg})$ de frangos de corte machos em relação aos níveis de proteína bruta das dietas (\%)

Por outro lado, de acordo com os resultados de Faria Filho et al. (2006) aves criadas em ambiente termoneutro 20 e $25^{\circ} \mathrm{C}$, alimentadas com dietas de baixa proteína, apresentaram resultados semelhantes ao tratamento controle. Também, Oliveira et al. (2007), não observaram efeitos dos níveis de PB sobre o ganho de peso, consumo de ração e conversão alimentar. De maneira semelhante, Gomide et al. (2007) concluíram que o nível de PB da dieta pode ser reduzido para $16 \%$ sem que haja prejuízo sobre as variáveis de desempenho, desde que a dieta inicial seja de acordo com as recomendações da literatura; porém diferentemente do presente trabalho essas dietas foram suplementadas com fitase. Rodrigues et al. (2008a) verificaram que aves alimentadas com dietas contendo $17 \%$ de PB e relação lisina digestível:proteína bruta de 5,9\% apresentam desempenho semelhante à dieta controle. Da mesma forma, Costa et al. (2001) não encontraram efeitos dos níveis de PB sobre o ganho de peso. Já, Gonzáles-Esquerra \& Leeson (2005) verificaram que a conversão alimentar melhora com o aumento dos níveis de proteína em qualquer temperatura. Os resultados indicaram que o maior nível de proteína promove melhor ganho de peso e conversão alimentar. Neste trabalho, não se observou melhoria na conversão alimentar com o aumento dos níveis de PB.

Diferentemente dos resultados deste trabalho, Kamran et al. (2004), Sabino et al. (2004), Rigueira et al. (2006) e Oliveira et al. (2007), não observaram efeitos dos níveis de PB sobre o consumo de dieta. Já, de acordo com
Silva et al. (2001), a diminuição dos níveis de PB apresentou efeito linear decrescente sobre o consumo de dieta. De acordo com esses autores, o aumento do nível de proteína da ração tem efeito estimulante no consumo de frangos de corte, em virtude, provavelmente da necessidade das aves de atenderem à deposição máxima de tecido magro na carcaça.

Os dados de consumo de dieta obtidos nesse trabalho, corroboram com os resultados obtidos por Aletor et al. (2000), Costa et al. (2001) e Kamram et al. (2008), que encontraram aumento linear do consumo com a diminuição dos níveis de PB. Por outro lado, Namroud et al. (2008), observaram diminuição do consumo quando as aves foram alimentadas com de menores níveis protéicos. De acordo com Leeson \& Summers (2005), aves que recebem dietas deficientes nutricionalmente tendem a aumentar o consumo de ração para suprir as deficiências dietéticas. Quanto maior a idade do frango, maior sua capacidade de aumentar o consumo para suprir as deficiências nutricionais.

\section{Rendimentos de carcaça e cortes}

Os resultados de rendimentos de carcaça e cortes de frangos alimentados com dietas contendo diferentes níveis de $P B$ encontram-se na tabela 3 . Não houve influência dos níveis de $\mathrm{PB}(\mathrm{P}>0,05)$ sobre o rendimento de carcaça, rendimento de coxa, asas e dorso. Entretanto o rendimento de peito apresentou efeito quadrático dos níveis de PB. O nível de PB para máximo rendimento de peito foi estimado em 18,28\% (Figura 4). 
Tabela 3 - Rendimento de carcaça e cortes de frangos de corte alimentados com dietas contendo diferentes níveis de PB.

\begin{tabular}{cccccc}
\hline Níveis de PB (\%) & R. Carcaça $(\%)$ & Rend. Peito $(\%)$ & Rend. Coxa $(\%)$ & Rend. Asas $(\%)$ & Rend. dorso \\
\hline 21 & 78,21 & 33,88 & 32,21 & 8,22 & 13,74 \\
19 & 78,47 & 34,60 & 29,86 & 8,24 & 14,24 \\
17 & 78,87 & 34,31 & 31,18 & 8,34 & 13,09 \\
15 & 78,33 & 33,66 & 30,82 & 8,29 & 13,89 \\
CV $(\%)$ & 1,71 & 4,57 & 4,29 & 4,74 & 9,48 \\
\hline Significancia & $\mathrm{ns}$ & $*$ & $\mathrm{~ns}$ & $\mathrm{~ns}$ & $\mathrm{~ns}$ \\
\hline
\end{tabular}

* = Significativo $(\mathrm{P}<0,05) ; \mathrm{ns}=$ não significativo $(\mathrm{P}>0,05)$

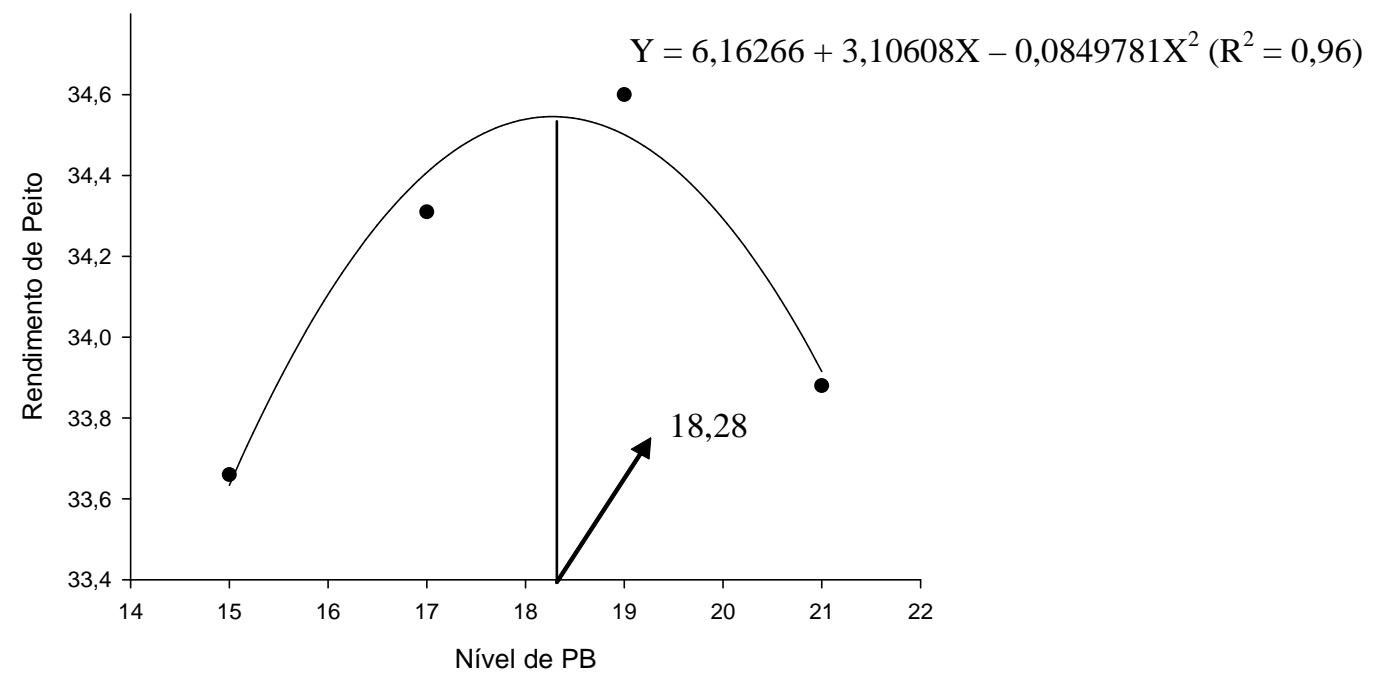

Figura 4 - Regressão do rendimento de peito (\%) de frangos de corte aos 42 dias em relação aos níveis de PB da $\operatorname{dieta}(\%)$.

Silva et al. (2001), Faria Filho et al. (2006), Rigueira et al. (2006), Oliveira et al. (2007), Kamram et al. (2008) e Rodrigues et al. (2008b); não encontraram diferenças estatísticas para rendimento de carcaça e cortes de frangos alimentados com diferentes níveis de PB. Todavia, Costa et al. (2001) encontraram efeito linear crescente para rendimento de peito de frangos de corte alimentados com dietas contendo 17,50 a 19,50\% de PB. Também Sabino et al. (2004) encontraram efeito linear para rendimento de carcaça com o aumento dos níveis de PB. De acordo com Leeson (1995), à medida que há incremento da ingestão protéica, em razão do maior conteúdo de proteína da dieta, há aumento do rendimento de peito.

Em relação aos dados obtidos neste trabalho, os rendimentos de peito nos níveis mais altos e mais baixos de PB não foram máximos. Nos níveis mais altos de $\mathrm{PB}$ da dieta, o pior rendimento de peito, pode estar relacionado à maior excreção nitrogenada com menor disponibilidade de aminoácidos e energia para síntese de proteína muscular. Em relação aos níveis mais baixos de proteína bruta (17 e $15 \%$ ), as dietas, provavelmente, não continham quantidade suficiente de proteína ou determinado(os) aminoácidos para máxima deposição de tecido muscular ou ainda alguma deficiência de aminoácidos pode ter ocorrido com a redução protéica da dieta. O nível de 18,28\% de PB foi, portanto, o que permitiu maior deposição de proteína muscular e melhor rendimento de peito. Resultado da maior eficiência de utilização da proteína.

Composição de carcaça de frangos de corte aos 42 dias de idade recebendo dietas com diferentes níveis de $\mathbf{P B}$.

Os dados de matéria seca (MS), proteína bruta (PB), extrato etéreo (EE) e matéria mineral (MM), de carcaças dos frangos aos 42 dias de idade alimentados com dietas 
contendo diferentes níveis protéicos encontram-se na tabela 4. Observou-se efeito quadrático do nível de PB sobre o conteúdo de matéria seca e efeito linear sobre o extrato etéreo. Para o conteúdo de PB e MM não houve efeito significativo. O máximo conteúdo de MS na carcaça foi estimado para uma dieta com 16,92\% de PB (Figura 5).

O conteúdo de MS parece estar relacionado ao aumento de gordura na carcaça. Aumentos dos teores de MS também foram encontrados por Aletor et al. (2000) com a redução protéica da dieta.

Aletor et al. (2000) também observaram aumento no teor de gordura na carcaça de frangos de corte alimentados com dietas com níveis mais baixos de PB. Aumento na percentagem de gordura na carcaça de animais alimentados com dietas contendo baixos níveis de proteína também foram encontrados por Cromwell et al. (1996), Tuitoek et al. (1997), Silva et al. (2003) e Gonzalez-Esquera \& Leeson (2005).
Em vários relatos da literatura, a diminuição de níveis protéicos leva ao aumento dos níveis de gordura da carcaça o que, provavelmente, está relacionado à economia de energia. Energia que está sendo economizada com a menor excreção nitrogenada proporcionada pelas dietas de menor teor protéico.

Em relação aos níveis de $\mathrm{PB}$ da carcaça Aletor et al. (2000), de maneira semelhante ao encontrado neste trabalho, verificaram que a percentagem de proteína depositada na carcaça não apresentou diferença significativa comparada à dieta controle.

Deve-se considerar que as aves têm exigências de aminoácidos e não de proteína bruta. Leeson \& Summers (1997) relataram redução na deposição de gordura com o aumento dos níveis de PB da dieta; mas com variação de 20 a $36 \%$ na PB da dieta existe apenas pequena variação no conteúdo de PB da carcaça. De acordo com Furlan et al.

Tabela 4 - Composição percentual de carcaça de frangos de corte aos 42 dias de idade recebendo dietas com diferentes níveis de Proteína Bruta

\begin{tabular}{ccccc}
\hline Níveis de PB(\%) & Matéria Seca $^{1}$ & Proteína Bruta & Extrato Etéreo $^{2}$ & Matéria Mineral $^{2}$ \\
\hline 21 & 31,98 & 17,67 & 11,26 & 2,67 \\
19 & 34,28 & 17,68 & 13,81 & 2,70 \\
17 & 34,19 & 17,27 & 14,07 & 2,65 \\
15 & 34,13 & 17,21 & 14,35 & 2,44 \\
CV $(\%)$ & 3,24 & 3,31 & 11,57 & 10,71 \\
\hline Significância & $*$ & ns & $*$ & ns
\end{tabular}

\begin{tabular}{ccccc}
\hline Significância & $*$ & ns & $*$ & ns \\
\hline$*$ significativo $(\mathrm{P}<0,05) ; \mathrm{ns}=$ não significativo $(\mathrm{P}>0,05)$ & & &
\end{tabular}

* = significativo $(\mathrm{P}<0,05)$; ns = não significativo $(\mathrm{P}>0,05)$

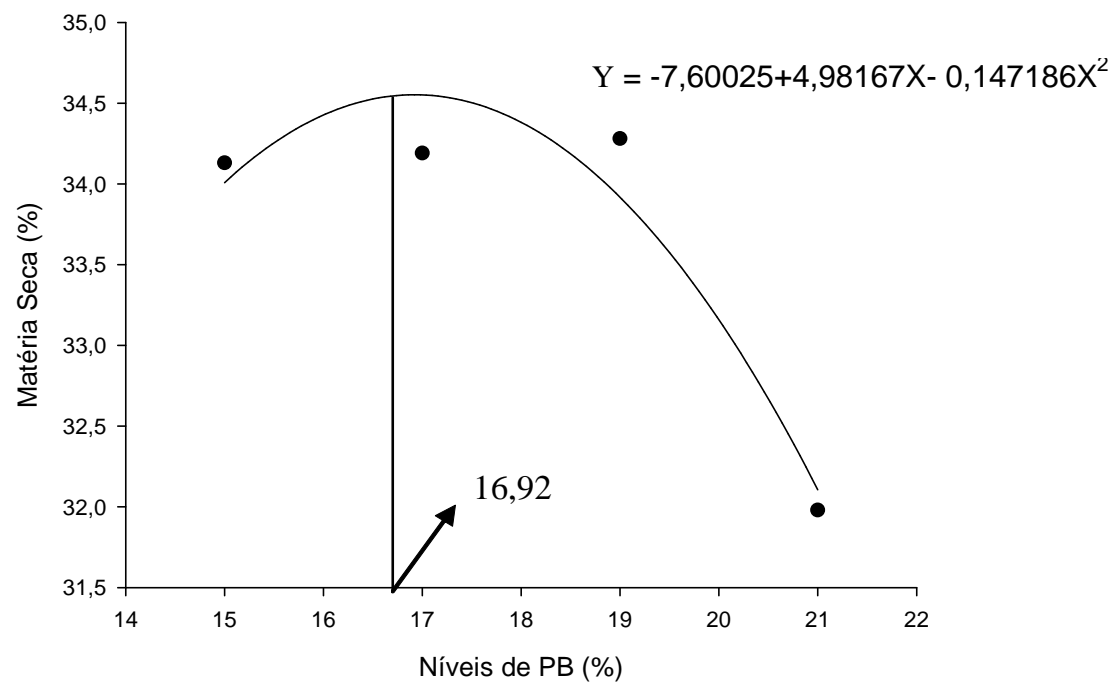

Figura 5 - Regressão dos teores de matéria seca (\%) nas carcaças de frangos de corte aos 42 dias de idade em relação aos níveis de PB da dieta. 
(2004), a deposição de aminoácidos na carcaça é préestabelecida pela ave, de acordo com sua informação genética, ou seja, existe um limite para a deposição diária de proteína independente da ingestão. Apesar disso, Gonzalez-Esquera \& Leeson (2005) observaram aumento na deposição de proteína na carcaça quando as aves consumiram dietas mais ricas em proteína.

Sendo um fator genético, era de se esperar que a deposição de proteína na carcaça não se alterasse com a redução protéica. Apesar de o desempenho dessas aves ter sido alterado pelos níveis de $\mathrm{PB}$, proporcionalmente, a deposição protéica não se alterou. A redução de proteína, neste trabalho teve efeito apenas no teor de MS e EE que pode estar relacionada à economia energética.

\section{CONCLUSÕES}

A diminuição dos níveis de proteína bruta das dietas leva a perdas de desempenho e deposição de gordura na carcaça de frangos de corte machos de 21 a 42 dias de idade.O melhor ganho de peso foi obtido com dietas contendo $19,28 \%$. O maior rendimento de peito foi obtido com $18,28 \%$ de PB.

\section{REFERÊNCIAS BIBLIOGRÁFICAS}

ALETOR, V.A.; HAMID, I.I.; NIEB, E.; PFEFFER, E. Lowprotein amino acid-supplemented diets in broiler chickens: effects on performance, carcass characteristics, whole-body composition and efficiencies of nutrient utilisation. Journal of Science and Food Agricultura, Easton, v.80, p.547-554, 2000.

BREGENDAHL, K.; SELL, J.L.; ZIMMERMAN, D.R. Effect of low-protein diets on growth performance and body composition of broiler chicks. Poultry Science, London, v.81, p.1156-1167, 2002.

CHENG, T.K.; HAMRE, M.L.; COON, C.N. Responses of broilers to dietary protein levels and amino acid supplementation to low protein diets at various environmental temperatures. Journal of Applied Poultry Research, Cambridge, v.6, p.18-33, 1997.

COSTA, F.G.; ROSTAGNO, H.S.; ALBINO, L.F.T.; GOMES, P.C.; TOLEDO, R.S. Níveis dietéticos de proteína bruta para frangos de corte de 1 a 21 e 22 a 42 dias de idade. Revista Brasileira de Zootecnia, Viçosa, v.30, n.5, p.1498-1505, 2001.

CROMWELL, G.L.; LINDERMANN, M.D.; PARKER, G.R.; LAURENT, K.M. Low protein, amino acid supplemented diets for growing-finishing pigs. Journal of Animal Science, Champaign, v.74, 1996.

FARIA FILHO, D.E.; ROSA, P.S.; FIGUEIREDO, D.F.; DAHLKE, F. Dietas de baixa proteína no desempenho de frangos criados em diferentes temperaturas. Pesquisa Agropecuária Brasileira, Brasília, v.41, p.101-106, 2006.

FURLAN, R.L.; FARIA FILHO, D.E.; ROSA, P.S.; MACARI, M. Does low-protein diet improve broiler performance under heat stress conditions? Revista Brasileira de Ciência Avícola, v.6, p.71-79, 2004.

GOMIDE, E.M.; RODRIGUES, P.B.; FREITAS, R.T.F.; FIALHO, E.T. Planos nutricionais com a utilização de aminoácidos e fitase para frangos de corte mantendo o conceito de proteína ideal nas dietas. Revista Brasileira de Zootecnia, Viçosa, v.36, n.6, p. 1769-1774, 2007.

GONZALEZ-ESQUERRA, R.; LEESON, S. Effects of acute versus chronic heat stress on broiler response to dietary protein. Poultry Science, London, v.84, p.15621569, 2005.

KAMRAN, Z.; SARWAR, M.; NISA, M.; NADEEM, M.A.; MAHMOOD, M.E. Effect of low-protein diets having constant energy-to-protein ratio on performance and carcass characteristics of broiler chickens from one to thirty-five days of age. Poultry Science, London, v.87, p.468-474, 2008.

LEESON, S. Nutrição e qualidade da carcaça de frangos de corte. In: CONFERENCIA APINCO DE CIENCIA E TECNOLOGIA AVICOLAS, 1995, Curitiba. Anais...Campinas: FACTA, 1995. p.118-123.

LEESON, S.; SUMMERS, D.J. Commercial poultry nutrition. 2.ed. Ontario: University Books, 1997.

LEESON, S.; SUMMERS, J.D. Commercial poultry nutrition. 3.ed. Ontario: University Books, 2005.

LEESON, S.; SUMMERS, J.D. Nutrition of the chicken. 4.ed. Ontario: University Books, 2001. 413p.

NAMROUD, N.F.; SHIVAZAD, M.; ZAGHARI, M. Effects of fortifying low crude protein diet with crystalline amino acids on performance, blood ammonia level, and excreta characteristics of broiler chicks.

Poultry Science, London, v.87, p.2250-2258, 2008. 
NAGATA, A. K.; RODRIGUES, P. B.; RODRIGUES, K. F.; FREITAS, R. T. F. de; ALBINO, L. F. T. ; FIALHO, E. T. Uso do conceito de proteína ideal em rações com diferentes níveis energéticos, suplementadas com fitase para frangos de corte de 1a 21 dias de idade. Ciência e Agrotecnologia, v.33, n.2, p. 599-605, mar./abr., 2009.

OLIVEIRA, W.; OLIVEIRA, R.F.M.; DONZELE, J.L.; ASSIS, A. Níveis de proteína bruta com suplementação de aminoácidos na ração de frangos de corte submetidos ao estresse de calor. In: REUNIÃO ANUAL DA SOCIEDADE BRASILEIRA DE ZOOTECNIA, 44., 2007, Joboticabal. Anais... Jaboticabal: UNESP, 2007.

RIGUEIRA, L.C.M.; ROSTAGNO, H.S.; ALBINO, L.F.T.; CARVALHO, D.C.O. Aplicação do conceito de proteína ideal em dietas com diferentes níveis protéicos para frangos de corte no período de 21 a 35 dias de idade. In: REUNIÃO ANUAL DA SOCIEDADE BRASILEIRA DE ZOOTECNIA, 43., 2006, João Pessoa. Anais... João Pessoa: Sociedade Brasileira de Zootecnia, 2006.

RODRIGUES, K.F.; RODRIGUES, P.B.; FREITAS, R.T.F.; BERTECHINI, A.G.; ALBINO, L.F.T.; FASSANI, E.J. Relação lisina digestível:proteína bruta em dietas para frangos de corte no período de 1 a 21 dias de idade. Desempenho e metabolismo. Revista Brasileira de Zootecnia, Viçosa, v.37, n.3, p.450-457, 2008a.

RODRIGUES, K.F.; RODRIGUES, P.B.; FREITAS, R.T.F.; FIALHO, E.T.; BERTECHINI, A.G. Desempenho e rendimento de carcaça de frangos de corte no período de 22 a 42 dias de idade alimentados com dietas contendo diferentes relações lisina digestível:proteína bruta. Revista Brasileira de Zootecnia, Viçosa, v.37, n.4, p.645652, $2008 b$.

ROSTAGNO, H.S. Tabelas brasileiras para aves e suínos: composição de alimentos e exigências nutricionais. Viçosa, MG: UFV, 2005. 186p.
ROSTAGNO, H.S.; ALBINO, L.F.T.; PÁES, L.E.; RODRIGUES, C. Uso da proteína ideal para formular dietas de frangos de corte. In: SEMINÁRIO TÉCNICO AJINOMOTO BIOLATINA, 2006, Campinas. Anais... Campinas: Ajinomoto Biolatina, 2006.

ROSTAGNO, H.S.; VARGAS JUNIOR, J.G.; ALBINO, L.F.T.; TOLEDO, R.S.; OLIVEIRA, J.E.; CARVALHO, D.C.O. Níveis de proteína e aminoácidos em rações de pinto de corte. Revista Brasileira de Ciência Avícola, Campinas, v.4, p.49, 2002. Suplemento.

SABINO, H.F.N.; SAKOMURA, N.K.; NEME, R.; FREITAS, E.R. Níveis protéicos na ração de frangos de corte na fase de crescimento. Pesquisa Agropecuária Brasileira, Brasília, v.39, n.5, p.407-412, 2004.

SILVA, D.J. Análise de alimentos: métodos químicos e biológicos. 2.ed. Viçosa, MG: UFV, 1990. 166p.

SILVA, J.H.V.; ALBINO, L.F.T.; NASCIMENTO, A.H. Níveis de energia e relações energia:proteína para frangos de corte de 22 a 42 dias de idade. Revista Brasileira de Zootecnia, Viçosa, v.30, n.6, p.1791-1800, 2001.

SILVA, J.H.V.; ALBINO, L.F.T.; NASCIMENTO, A.H. Estimativas da composição anatômica da carcaça de frangos de corte com base no nível de proteína da ração e peso da carcaça. Revista Brasileira de Zootecnia, Viçosa, v.32, n.2, p.344-352, 2003.

SKLAN, D.; PLAVINIC, I. Interaction between dietary crude protein and essencial amino acid intake on performance in broilers. British Poultry Science, London, v.43, p.442-449, 2002.

TUITOEK, K.; YOUNG, L.G.; de; LANGE, C.F.M.; KERR, B.J. The effect of reducing excess dietary amino acids on growing-finishing pig performance: An evaluation of the ideal protein concept. Journal of Animal Science, Champaign, v.75, p.1575-1583, 1997. 